\title{
Epidemiological characteristics of patients with idiopathic normal pressure hydrocephalus in Japan: analysis of the treatment
}

\author{
Madoka Nakajima*, Masakazu Miyajima, Chihiro Akiba, Ikuko Ogino, Hajime Arai \\ From Hydrocephalus 2015 \\ Banff, Canada. 18-21 September 2015
}

\section{Introduction}

To clarify the epidemiological and clinical characteristics of idiopathic normal pressure hydrocephalus (iNPH) in Japan, a nationwide epidemiological survey was conducted, focusing on treatment analysis.

\section{Methods}

Study participants were selected according to hospital bed capacity, using a random sampling method. In a primary survey, the number of iNPH patients in each hospital department during the year 2012 was estimated for stratification of institutions and next, in a secondary survey, selected patients provided detailed information, determining the clinical and epidemiological features of interest.

\section{Results}

In the primary survey 1804 clinical departments responded (recovery rate: $42.7 \%$ ) for 3079 individuals, including 1815 individuals who underwent shunt surgery. The estimated annual number of patients receiving treatment was 13,000 (95\% CI: 10000 to 16000). The estimated prevalence rate for hospital-based patients in 2012 was 10.2 individuals per 100,000.

Analyses were conducted on 1495 respondents (885 males (59.2\%): age 77.9 $\pm 6.30(\mathrm{SD})$ years; and 610 females (40.8\%): age 78.0 \pm 6.41 years. Results showed $992 \mathrm{iNPH}$ patients $(66.1 \%)$ treated with shunt surgery, 547 patients (77.6 \pm 6.12 yo) with lumboperitoneal (LPS), 428 patients (76.51 \pm 6.19 yo) with ventriculoperitoneal (VPS) and 17 with vetriculoatrial (VAS) shunting. Four patients having both LPS and VPS.

In 120 out of 992 shunted patients were recorded complications (12.1\%), including 77 out of 547 patients

\footnotetext{
* Correspondence: madoka66@juntendo.ac.jp

Juntendo University School of Medicine, Japan
}

with LPS and 43 out 428 patients with VPS, without statistically significant difference between the two subgroups $(\mathrm{p}=0.092)$.

Therapeutic efficacy exceeded 90\% with improvement of 1 point or higher on the modified Rankin Scale (mRS) in $56 \%$. Age and Alzheimer's Disease were factors with a negative impact on the therapeutic prognosis, with odds ratio of 1.029 95\%CI (1.013-1.047) p=0.001, and $1.36595 \%$ CI (1.008-1.849) $\mathrm{p}=0.044$, respectively. They had significant impact on the prognosis of improvement according to mRS.

\section{Conclusions}

We reported hospital based survey study in Japan, providing the main characteristics of iNPH epidemiology and management for 2012 .

Published: 18 September 2015

\section{References}

1. Nakajima M, Miyajima M, Ogino I, Sugano H, Akiba C, Miyata H, Karagiozov KL, Arai $\mathrm{H}$ : Use of external lumbar cerebrospinal fluid drainage and lumboperitoneal shunts with Strata NSC valves in idiopathic normal pressure hydrocephalus: a single-center experience. World Neurosurgery 2015, 83(3):387-393.

2. Nakajima M, Sugano H, limura Y, Higo T, Nakanishi H, Shimoji K, Karagiozov K, Miyajima M, Arai H: Sturge-Weber syndrome with spontaneous intracerebral hemorrhage in childhood. J Neurosurg Pediatr 2014, 13(1):90-3

3. Nakajima M, Miyajima M, Ogino I, Hagiwara Y, Arai H: Brain Localization of Leucine-Rich a2 Glycoprotein and its Role, Hydrocephalus. Acta Neurochirgica Supplement 2012, 113:97-101.

4. Nakajima M, Miyajima M, Ogino I, Arai H: Leucine-rich-alpha-2glycoprotein is a marker of idiopathic normal pressure hydrocephalus. Acta Neurochir 2011, 153:1339-1346.

doi:10.1186/2045-8118-12-S1-O39

Cite this article as: Nakajima et al:: Epidemiological characteristics of patients with idiopathic normal pressure hydrocephalus in Japan: analysis of the treatment. Fluids and Barriers of the CNS 2015 12(Suppl 1): O39. 